\title{
Erector Spinae Plane Block and Paravertebral Block for Breast Surgery: A Retrospective Propensity-Matched Noninferiority Trial
}

This article was published in the following Dove Press journal:

Journal of Pain Research

\author{
Yuki Aoyama (D' \\ Shinichi Sakura $\mathbb{D D}^{\prime}$ \\ Ritsuko Tsuchiya' \\ Aumjit Wittayapairoj ${ }^{1,2}$ \\ Yoji Saito (D) \\ 'Department of Anesthesiology, Faculty \\ of Medicine, Shimane University, Izumo \\ City, Shimane, Japan; ${ }^{2}$ Department of \\ Anesthesiology, Faculty of Medicine, \\ Khon Kaen University, Khon Kaen, \\ Thailand
}

Purpose: Thoracic paravertebral block (TPVB) is an established analgesic technique for breast surgery although it is technically challenging. Erector spinae plane block (ESPB) requires less technical expertise and may be an alternative to TPVB. However, whether ESPB has similar analgesic effects to TPVB for breast surgery is still inconclusive. Moreover, information on sensory blockade of ESPB is scarce. Accordingly, we conducted this retrospective propensity-matched study to see if ESPB could provide comparable analgesic effects to TPVB in patients undergoing breast surgery. We also compared cutaneous sensory block levels after the two techniques.

Patients and Methods: In this retrospective cohort study, we analyzed data saved in our database and compared the two techniques using a propensity matching method. The data of patients who underwent unilateral breast surgery under general anesthesia with the addition of either TPVB or ESPB were identified. We considered that the analgesic efficacy of ESPB was noninferior to TPVB if both postoperative fentanyl consumption and area under the curve (AUC) for pain scores within $24 \mathrm{~h}$ were within $50 \mu \mathrm{g}$ and $240 \mathrm{~mm} \cdot \mathrm{h}$ margins, respectively. Cutaneous sensory block levels, additional analgesic requirements, and complications were also compared between the two groups.

Results: Among 93 patients, 30 patients for each group were matched. Both postoperative fentanyl consumption and AUC for pain scores after ESPB were noninferior to those after TPVB. ESPB did not produce sensory blockade consistently, and the number of dermatomes was smaller after ESPB [1 (0-3)] [median (interquartile range)] than after TPVB [4 (2-5)] $(\mathrm{P}=0.002)$. No serious complications related to blocks were observed.

Conclusion: ESPB and TPVB provided comparable postoperative analgesia for $24 \mathrm{~h}$ in patients undergoing breast surgery. Dermatomal sensory blockade was, however, less apparent and narrower after ESPB than after TPVB.

Keywords: nerve block, anesthesia and analgesia, pain, postoperative, mastectomy

\section{Introduction}

Adequate acute postoperative pain control is important for patients undergoing breast surgery because the pain may be severe and long-lasting. ${ }^{1}$ Thoracic paravertebral block (TPVB) is an established technique after breast surgery for providing good analgesia, reducing opioid consumption and decreasing the incidence of chronic pain. ${ }^{2-5}$ However, TPVB is technically challenging even with ultrasound and may be associated with serious complications such as pneumothorax. ${ }^{6,7}$ More than a few clinicians hesitate to use this technique in daily practice.
Correspondence: Shinichi Sakura Department of Anesthesiology, Faculty of Medicine, Shimane University, Izumo City, Shimane, Japan

Email ssakura@med.shimane-u.ac.jp 
Recently, several thoracic wall blocks have been introduced including erector spinae plane block (ESPB), a new interfascial plane block which requires less technical expertise and is an expected alternative to TPVB. ${ }^{8}$ Previous case reports have described its analgesic efficacy in patients with rib fracture and chronic pain, and after lung resection, spine surgery and breast surgery. ${ }^{8-12}$ Several randomized controlled trials have shown reduction in postoperative opioid consumption after ESPB in patients undergoing breast surgery. ${ }^{10-12}$ However, whether ESPB has similar analgesic effects to TPVB for breast surgery is still inconclusive. ${ }^{11,13,14}$ Moreover, information on sensory blockade after ESPB is still mostly limited in case reports. ${ }^{15-17}$ Injectate administered by ESPB is expected to make a wide spread in the craniocaudal direction, yet the results of cadaveric studies show inconsistent and unpredictable dye spread with little spread to the paravertebral space. ${ }^{18-23}$

Accordingly, this retrospective propensity-matched study was conducted to see if ESPB could provide comparable analgesic effects to TPVB in patients undergoing breast surgery using data saved in our departmental registry. We also compared the distribution of sensory blockade after TPVB and ESPB.

\section{Patients and Methods}

This retrospective cohort study was approved by the institutional ethical committee of Shimane University Hospital (study number: 4373) on February 28, 2020, and conducted in accordance with the rules of the Declaration of Helsinki. The data were obtained from the registry of regional anesthesia saved in the department and the medical records of individual patients. Written informed consent was waived because the study was limited to the pre-existing data. Registry data includes detailed information on block performance, cutaneous sensory blockade, postoperative pain severity and complications in the early postoperative period (for at least $24 \mathrm{~h}$ ). Patients' names and other forms of identification were deleted before analysis. We have collected these data as a care standard since we started to perform ESPB in patients undergoing breast cancer surgery, because ESBP is a newly developed technique with no available information regarding either its analgesic effects or its distribution of cutaneous sensory blockade. The registry also includes data of patients receiving other blocks including TPVB conducted during the same time frame. We extracted data of all female patients who underwent unilateral breast cancer surgery under general anesthesia with the addition of either TPVB (PVB group) or ESPB (ESPB group) conducted preoperatively under ultrasound guidance between June 2018 and January 2020 and compared these two techniques within the propensity-matched patients. Patients aged 20-90 years with an American Society of Anesthesiologists physical status $1-3$ and body mass index (BMI) $<40 \mathrm{~kg} / \mathrm{m}^{2}$ were considered eligible for this study. Patients with chronic opioid use, disability to communicate, paralysis or neurological disability on the trunk and extensive surgery such as reconstructive surgery (with or without insertion of tissue expander) were excluded.

The routine general anesthetic management and block techniques were based on our hospital's breast cancer surgery care standard. Patients received either TPVB or ESPB in the prone position before induction of general anesthesia with standard monitoring. The choice of peripheral nerve blocks was based upon patient preference and/or at the discretion of the anesthesiologist. Midazolam 1-2 mg and fentanyl $50 \mu \mathrm{g}$ were given for sedation before block. Regional anesthesiologists (R. T. and A.W.) familiar with both techniques performed all the blocks. TPVB was conducted at both the T3 and T5 levels, and ESPB was conducted at the T5 level. The vertebral level, in which the block was conducted, was identified by counting ribs cephalad to caudal using ultrasound image and then marked on the skin with a felttip pen. The skin was prepared with chlorhexidine and infiltrated with $1 \%$ mepivacaine. A 21 -gauge block needle (Sonoplex 100 mm, PAJUNK, Geisingen, Germany) was used for both blocks. TPVB was performed by the intercostal transverse in-plane technique. ${ }^{24}$ An $8-3 \mathrm{MHz}$ convex transducer (Sonosite X-Porte, Sonosite Fujifilm, Bothell, WA, USA) was positioned parallel to the intercostal space to visualize the transverse process and paravertebral space. The needle was inserted from the lateral to medial direction in the ultrasound image. A small volume of normal saline was injected and the anterior displacement of pleura was visualized to confirm the correct needle tip position. Then, $10 \mathrm{~mL}$ of $0.5 \%$ ropivacaine was injected for each level with negative aspiration of blood and air. For ESPB, a 15-6 MHz linear transducer (Sonosite X-Porte, Sonosite Fujifilm, Bothell, WA, USA) was placed parasagittally to the trunk at $2-3 \mathrm{~cm}$ lateral from the midline and adjusted to visualize the 5 th transverse process. The needle was inserted from the caudal to cranial direction under ultrasound image to contact with the transverse process. After normal saline was injected and interfascial spread was confirmed, $20 \mathrm{~mL}$ of $0.5 \%$ ropivacaine was injected into the fascial 
plane between the transverse process and erector spinae muscle.

Although the intraoperative management of general anesthesia varies slightly among anesthesiologists caring for each patient, general anesthesia was induced with fentanyl and propofol and the airway was secured with a laryngeal mask or tracheal intubation. Propofol and remifentanil were continuously infused intraoperatively and acetaminophen was intravenously given at skin closure. During surgery, additional fentanyl was injected at the discretion of the anesthesiologist. After surgery, patients were taken to the ward where they stayed for at least one day. All patients received intravenous patientcontrolled analgesia (PCA) using fentanyl 20-30 $\mu \mathrm{g}$ with no basal infusion and 10 minutes lock out time by electronic infuser pump (i-Fusor Plus, JMS, Hiroshima, Japan). Regular analgesics consisted of loxoprofen $180 \mathrm{mg} /$ day. Flurbiprofen axetil and acetaminophen were used for rescue analgesia when the pain was not well controlled despite PCA use.

\section{Outcomes}

Our primary outcomes were the postoperative fentanyl consumption and area under the curve (AUC) for visual analogue scale pain scores (VAS: 0, no pain; 100, worst pain imaginable) at rest during $24 \mathrm{~h}$. We hypothesized that the analgesic efficacy of ESPB was noninferior to TPVB. We considered ESPB was noninferior to TPVB if ESPB was noninferior for the two primary outcomes. Secondary outcomes included intraoperative opioid consumption, VAS on movement of the upper arm, rescue analgesic requirements, postoperative nausea and vomiting, cutaneous sensory blockade, time needed for block and complications. Postoperative fentanyl requirement was extracted from the infuser pump memory. VAS pain scores assessed at 6, 12 and $24 \mathrm{~h}$ after block procedures were collected and AUC was calculated. Cutaneous sensory blockade was assessed as the care standard at 15 minutes after block (before induction of general anesthesia), immediately after surgery, 6 and $12 \mathrm{~h}$ after block by loss of cold sensation using a small ice pack on the anterior axillary line. The time required for block performance (insertion to removal of the block needle) was also collected and compared between the two groups. Ultrasound observations of the lung were conducted after block procedure to detect pneumothorax. $^{25}$

\section{Statistical Analysis}

Propensity score analysis was performed to balance possible confounders between the two groups to prevent bias related to the initial selection of the patients. Age, body mass index, American Society of Anesthesiologists physical status, surgical procedure, surgical time and drain placement were considered as confounders as identified in literature and based on clinical knowledge. ${ }^{26,27}$ Although the surgeon is considered as a confounder in other studies, ${ }^{26,27}$ we did not include it in our confounders because the same operation team conducted all our surgeries. The multivariable logistic regression model was used to calculate propensity scores with the caliper set at 0.2 standard difference of the estimated propensity score. Matching was performed by the nearest-neighbor algorithm without replacement and patients who received TPVB (PVB group) and ESPB (ESPB group) were matched by a $1: 1$ ratio. The standardized difference was estimated to evaluate covariate balance, whereby an absolute standardized difference above 0.1 represents meaningful imbalance.

Noninferiority was claimed when the upper limit of the 95\% confidence interval (CI) was less than the noninferiority margin which was determined based on literature and our preliminary data. A $30 \mathrm{mg}$ difference in oral morphine consumption (equally to $300 \mu \mathrm{g}$ of intravenous fentanyl) is generally considered as the minimum that is clinically meaningful; ${ }^{27}$ however, our preliminary data showed that most patients consumed less opioids postoperatively. Considering that 20-30 $\mu \mathrm{g}$ of fentanyl was used as a single dose for PCA, we set the noninferiority margin at $50 \mu \mathrm{g}$ for postoperative fentanyl consumption. VAS pain scores of $10-13 \mathrm{~mm}$ have been estimated to be the minimum clinically important difference. ${ }^{28,29}$ We considered a difference of $10 \mathrm{~mm}$ to be indicative of noninferiority, and thus, the margin for AUC of VAS within $24 \mathrm{~h}$ was set at $240 \mathrm{~mm} \cdot \mathrm{h}$. The postoperative fentanyl consumption was assumed to be non-normally distributed and the Hodges-Lehman estimator was used to calculate the $95 \%$ CIs of the median difference.

Statistical analysis was performed using SPSS for Windows version 23.0 software (SPSS, Inc., Chicago, IL, USA). Other analyses between the two groups were conducted using two-tailed Student's $t$-test, Mann-Whitney $U$-test and chi-square test or Fisher's exact test as appropriate and the value were expressed as mean \pm standard difference, median values with interquartile range and 
number (\%), respectively. A p value $<0.05$ was considered statistically significant.

\section{Results}

Ninety-three patients were identified for analysis (38 patients and 55 patients for PVB and ESPB groups, respectively) (Figure 1). Propensity score matching resulted in 30 patients for each group. The demographic and surgical characteristics of the patients were comparable after matching (Table 1). The intraoperative fentanyl and remifentanil doses were similar for both groups. VAS at rest at $6 \mathrm{~h}$ was significantly lower in the PVB group compared with the ESPB group both before and after matching. VAS on movement, requirements for rescue analgesics, incidence of postoperative nausea and vomiting were not different within $24 \mathrm{~h}$ (Table 2).

The sample size of 30 per group provided $99 \%$ power to detect noninferiority for both postoperative fentanyl consumption and AUC for VAS. Postoperative fentanyl consumption was $25(0-64) \mu \mathrm{g}$ and 51 (23-138) $\mu \mathrm{g}$ in the PVB and ESPB groups, respectively $(\mathrm{P}=0.084)$ for the matched cohort. The median difference and 95\% CI between the two groups (ESPB group - PVB group) was 20 (0 to 47) $\mu \mathrm{g}$, and the upper limit was below the margin of $50 \mu \mathrm{g}$, which suggests that ESPB was noninferior to TPVB. AUC of VAS at rest was $300 \pm 289 \mathrm{~mm} \cdot \mathrm{h}$ and 381 $\pm 226 \mathrm{~mm} \cdot \mathrm{h}$ in the PVB and ESPB groups, respectively $(\mathrm{P}=0.254)$. The mean difference was $80.3 \quad(-59$ to 220) $\mathrm{mm} \cdot \mathrm{h}$, which was also under the noninferiority limit of $240 \mathrm{~mm} \cdot \mathrm{h}$ (Figure 2). The results of cutaneous sensory assessment showed that sensory blockade after TPVB and ESPB ranged from T2 to T10 and from T1 to T10 dermatomes, respectively. A significantly higher percentage of patients developed sensory blockade on the T3 and T5 dermatomes in the PVB group than in the ESPB group (Figure 3). Sensory blockade was observed in a significantly higher percentage of patients in the PVB group (96.4\%) than in the ESPB group (66.7\%) immediately after surgery $(\mathrm{P}=0.005)$. The number of dermatomes with sensory blockade was also significantly greater in patients given TPVB up to $6 \mathrm{~h}$ (Table 3 ). The median number of dermatomes with sensory blockade after ESPB was $0-1$ in all time points up to $12 \mathrm{~h}$. The time needed for block performance was significantly shorter for ESPB (Table 3). No serious complications, including pneumothorax, related to blocks were observed.

\section{Discussion}

This propensity-score matched retrospective cohort study showed that the difference between TPVB and ESPB in both postoperative fentanyl consumption and AUC for VAS within $24 \mathrm{~h}$ were under the noninferiority margin,

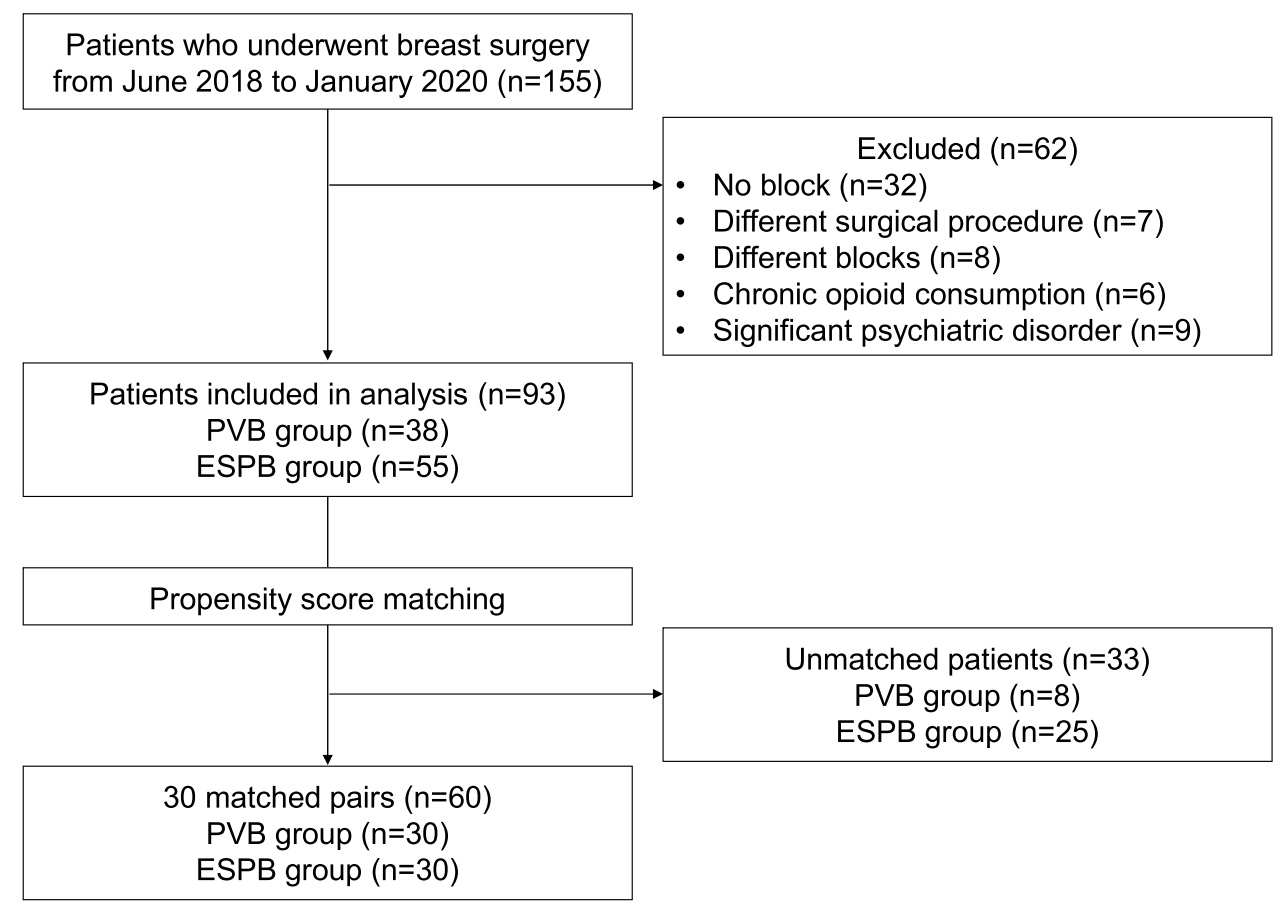

Figure I Flow diagram of case selection. 
Table I Patient Demographics Before and After Propensity Score Matching

\begin{tabular}{|c|c|c|c|c|c|c|}
\hline & \multicolumn{3}{|c|}{ Total population } & \multicolumn{3}{|c|}{ Propensity-matched population } \\
\hline & $\begin{array}{l}\text { PVB group } \\
(n=38)\end{array}$ & $\begin{array}{l}\text { ESPB group } \\
(n=55)\end{array}$ & $P$ value & $\begin{array}{l}\text { PVB group } \\
(n=30)\end{array}$ & $\begin{array}{l}\text { ESPB group } \\
(n=30)\end{array}$ & $P$ value \\
\hline Age, y & $57 \pm 17$ & $60 \pm 13$ & 0.433 & $57 \pm 17$ & $57 \pm 13$ & 0.966 \\
\hline BMI, $\mathrm{kg} / \mathrm{m}^{2}$ & $22 \pm 4$ & $22 \pm 4$ & 0.730 & $22 \pm 4$ & $22 \pm 4$ & 0.992 \\
\hline $\begin{array}{l}\text { ASA-PS, n (\%) } \\
\qquad \begin{array}{l}1 \\
2 \\
3\end{array}\end{array}$ & $\begin{array}{l}8(21.1 \%) \\
30(78.9 \%) \\
0(0 \%)\end{array}$ & $\begin{array}{l}10(18.2 \%) \\
43(78.2 \%) \\
2(3.6 \%)\end{array}$ & 0.477 & $\begin{array}{l}8(26.7 \%) \\
22(73.3 \%) \\
0(0 \%)\end{array}$ & $\begin{array}{l}7(23.3 \%) \\
23(76.7 \%) \\
0(0 \%)\end{array}$ & 1.000 \\
\hline $\begin{array}{l}\text { Type of surgical procedure } \\
\text { Partial mastectomy + SLNB, n (\%) } \\
\text { Partial mastectomy + ALNB, n (\%) } \\
\text { Mastectomy + SLNB, n (\%) } \\
\text { Mastectomy + ALNB, n (\%) }\end{array}$ & $\begin{array}{l}13(34.2 \%) \\
3(7.9 \%) \\
16(42.1 \%) \\
6(15.8 \%)\end{array}$ & $\begin{array}{l}31(56.4 \%) \\
3(5.5 \%) \\
14(25.5 \%) \\
7(12.7 \%)\end{array}$ & 0.202 & $\begin{array}{l}12(40.0 \%) \\
3(10.0 \%) \\
10(33.3 \%) \\
5(16.7 \%)\end{array}$ & $\begin{array}{l}13(43.3 \%) \\
2(6.7 \%) \\
11(36.7 \%) \\
4(13.3 \%)\end{array}$ & 0.941 \\
\hline Drain (yes), n (\%) & $24(63.2 \%)$ & 21 (38.2\%) & 0.021 & $17(56.7 \%)$ & $17(56.7 \%)$ & 1.000 \\
\hline Operation time, min & $129 \pm 54$ & $134 \pm 55$ & 0.656 & $|3| \pm 57$ & $|33 \pm 6|$ & 0.931 \\
\hline
\end{tabular}

Note: Data are presented as mean \pm standard deviation or number of patients (\%).

Abbreviations: PVB, paravertebral block; ESPB, erector spinae plane block; ASA-PS, American Society of Anesthesiologists physical status; BMI, body mass index; SLNB, sentinel lymph node biopsy; ALND, axillary lymph node dissection.

Table 2 Intraoperative Opioid Dose and Postoperative Patient Data Regarding Pain Scores, Analgesic Requirements and Postoperative Nausea and Vomiting Before and After Propensity Score Matching

\begin{tabular}{|c|c|c|c|c|c|c|}
\hline & \multicolumn{3}{|c|}{ Total population } & \multicolumn{3}{|c|}{ Propensity-matched population } \\
\hline & $\begin{array}{l}\text { PVB group } \\
(n=38)\end{array}$ & $\begin{array}{l}\text { ESPB group } \\
(n=55)\end{array}$ & $P$ value & $\begin{array}{l}\text { PVB group } \\
(n=30)\end{array}$ & $\begin{array}{l}\text { ESPB group } \\
(n=30)\end{array}$ & $P$ value \\
\hline Fentanyl during surgery, $\mu g$ & $225(150-300)$ & $200(175-250)$ & 0.768 & $200(150-275)$ & $250(200-300)$ & 0.514 \\
\hline Remifentanil during surgery, $\mu \mathrm{g}$ & $700(500-975)$ & $900(675-1325)$ & 0.064 & $800(550-\mid 400)$ & $700(400-1000)$ & 0.093 \\
\hline \multicolumn{7}{|l|}{ VAS at rest } \\
\hline $6 \mathrm{~h}$ & $10(0-25)$ & $20(15-36)$ & 0.009 & $10(0-20)$ & $20(17-36)$ & 0.017 \\
\hline $12 \mathrm{~h}$ & $16(0-30)$ & $20(15-40)$ & 0.059 & $13(0-30)$ & $23(15-40)$ & 0.084 \\
\hline $24 \mathrm{~h}$ & $9(0-18)$ & $12(0-20)$ & 0.639 & $6(0-18)$ & $17(0-20)$ & 0.507 \\
\hline \multicolumn{7}{|l|}{ VAS on movement } \\
\hline $6 \mathrm{~h}$ & $26(19-40)$ & $38(20-45)$ & 0.174 & $24(16-40)$ & $31(20-50)$ & 0.234 \\
\hline $12 \mathrm{~h}$ & $38(17-57)$ & $35(20-55)$ & 0.765 & $30(16-45)$ & $37(20-60)$ & 0.502 \\
\hline $24 \mathrm{~h}$ & $32(\mid I-4 I)$ & $21(17-43)$ & 0.851 & $2 I(8-4 I)$ & $27(18-45)$ & 0.443 \\
\hline Rescue analgesics required, time & $0(0-1)$ & $0(0-1)$ & 0.377 & $I(0-I)$ & $0(0)$ & 0.167 \\
\hline Nausea, n (\%) & 7 (18.4\%) & $16(29.1 \%)$ & 0.329 & 7 (23.3\%) & 7 (23.3\%) & 1.000 \\
\hline Vomiting, n (\%) & $4(10.5 \%)$ & $5(9.1 \%)$ & 1.000 & $4(13.3 \%)$ & $0(0 \%)$ & 0.112 \\
\hline Antiemetic use, n (\%) & 7 (I8.4\%) & $13(23.6 \%)$ & 0.615 & $5(16.7 \%)$ & $4(13.3 \%)$ & 1.000 \\
\hline
\end{tabular}

Note: Data are presented as median (interquartile range) or number of patients (\%).

Abbreviations: PVB, paravertebral block; ESPB, erector spinae plane block; VAS, visual analogue scale. 


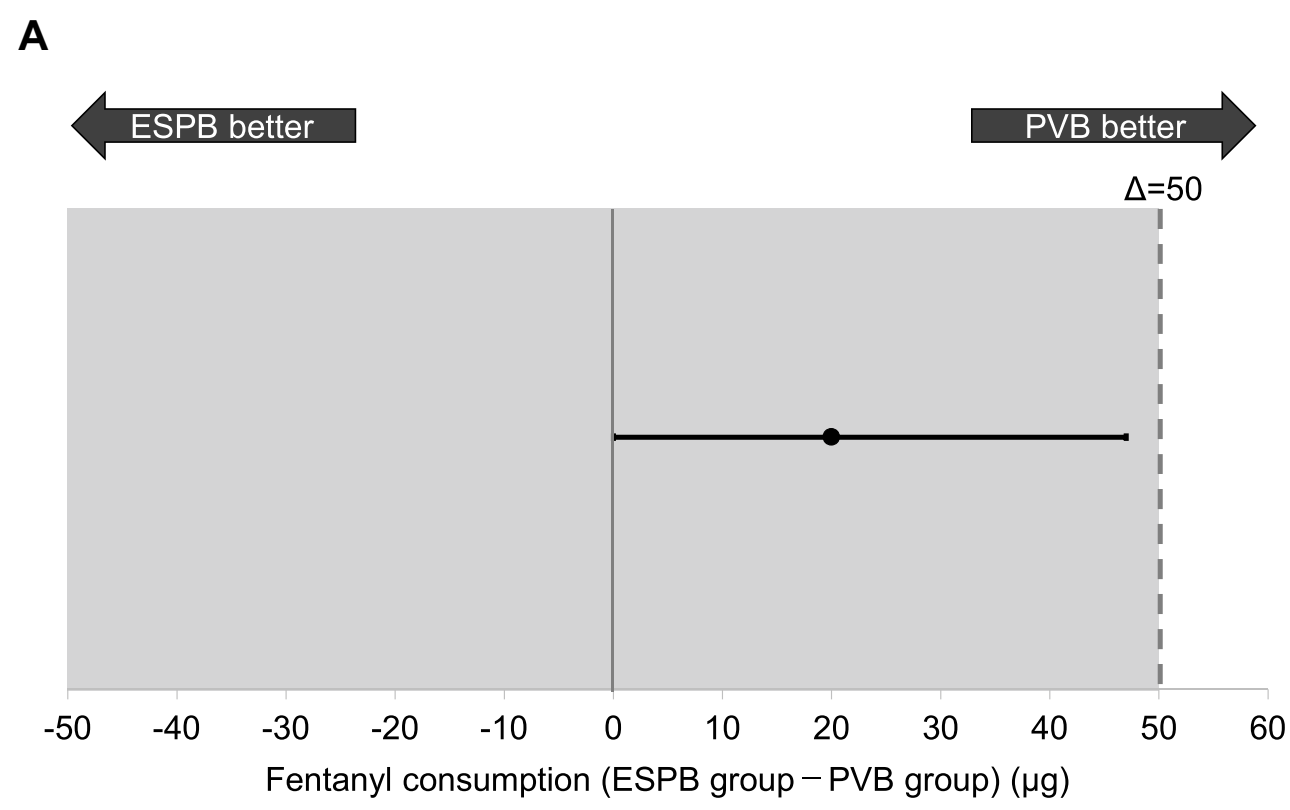

B

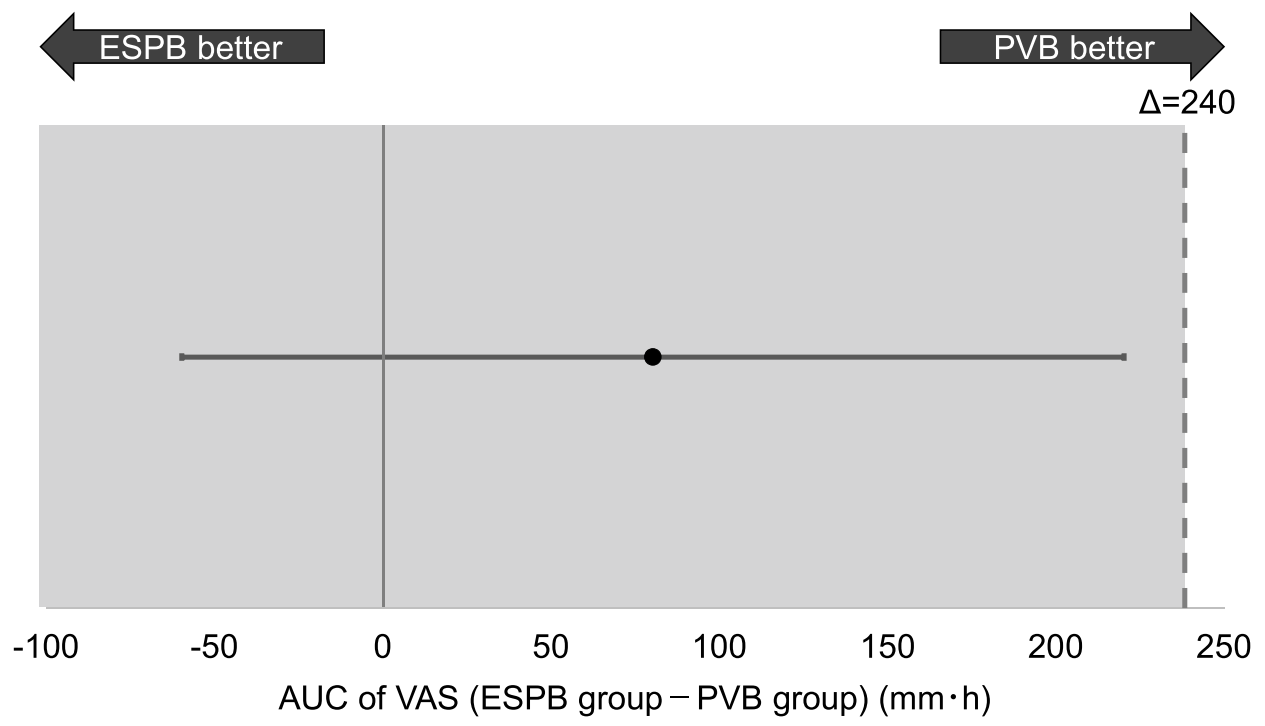

Figure 2 Treatment difference for postoperative fentanyl consumption (A) and area under the curve of visual analogue scale pain scores at rest (B) within $24 \mathrm{~h}$. The point shows the median and mean difference between the two groups for postoperative fentanyl consumption and area under the curve of pain scores, respectively. Error bars represents $95 \%$ confidence intervals of the difference. The dashed line designates the noninferiority margin $(\Delta)$ and the tinted area indicates zone of noninferiority. Abbreviations: PVB, paravertebral block; ESPB, erector spinae plane block; AUC, area under the curve; VAS, visual analogue scale.

suggesting that the analgesic effects of ESPB were comparable with those of TPVB in patients undergoing unilateral breast surgery. These findings are consistent with the results of previous studies. ${ }^{11,13}$ Gürkan et al compared 3 groups of patients who received ESPB, TPVB or no intervention before unilateral breast surgery and found that morphine consumption for $24 \mathrm{~h}$ postoperatively was similar between both block groups, but was significantly smaller in both block groups compared with the control group. ${ }^{11}$

Although we found that the two blocks were comparable regarding our primary outcomes, the results of our secondary outcomes suggest that the two blocks do not act similarly. In the present study, ESPB did not produce sensory blockade as consistently as TPVB and the median number of dermatomes with loss of cold sensation after ESPB was almost zero. The 


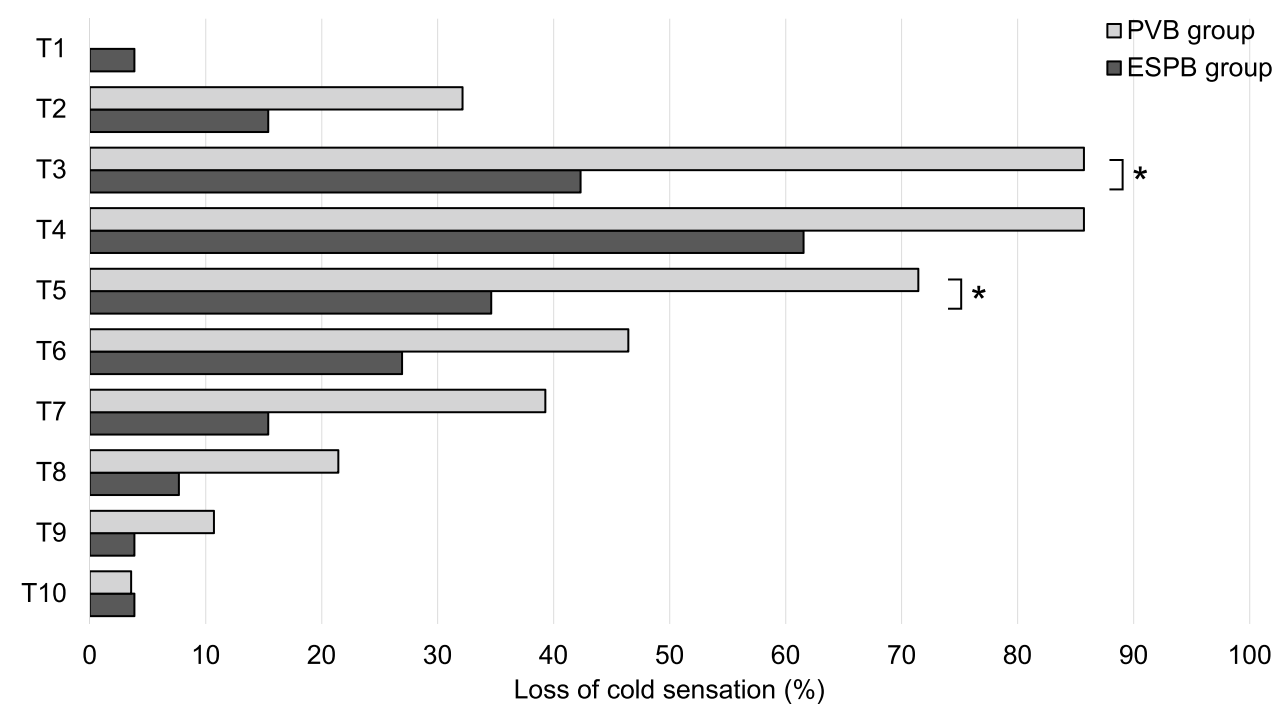

Figure 3 Cutaneous sensory blockade observed immediately after surgery. Results are presented as a percentage of the patients in matched cohort. Note: ${ }^{*} \mathrm{P}$ value of less than 0.05 .

Abbreviations: PVB, paravertebral block; ESPB, erector spinae plane block.

results appear to conflict with most case reports that have described a fairly large number of dermatomal sensory blockade produced by ESPB. ${ }^{15}$ However, as is often the case with case reports showing new techniques, the authors are likely to have presented only successful cases. To the best of our knowledge, there is only one clinical study showing the results of anesthetized dermatomes after ESPB. Taketa et al injected $20 \mathrm{~mL}$ of $0.2 \%$ levobupivacaine at $\mathrm{T} 4$ or $\mathrm{T} 5$ for ESPB to find that patients undergoing video-assisted thoracic surgery developed sensory blockade to pinprick with the median of 3.9 dermatomes on the anterior axillary line. ${ }^{30}$ The difference between the results of their study and ours may be explained by different definitions of sensory blockade. Taketa's study defined anesthetized dermatomes as areas of reduced sensitivity as compared with the contralateral side but not loss of sensation that was adapted in the present study.

The two blocks also differed in the analgesic effects at the early time point. We found that VAS at rest at $6 \mathrm{~h}$ was significantly higher after ESPB than after TPVB. The results are also similar to those of previous clinical studies showing significantly higher pain scores up to around $6 \mathrm{~h}$ after ESPB compared with after TPVB in patients undergoing breast surgery. ${ }^{11,14}$ Swisher et al showed that TPVB as compared with ESPB provided superior analgesia and reduced opioid consumption during Post-anesthesia Care Unit (PACU) stay

Table 3 Time Needed for Block Procedure and Number of Dermatomes with Loss of Cold Sensation After Paravertebral Block (PVB) and Erector Spinae Plane Block (ESPB)

\begin{tabular}{|c|c|c|c|c|c|c|}
\hline & \multicolumn{3}{|c|}{ Total population } & \multicolumn{3}{|c|}{ Propensity-matched population } \\
\hline & $\begin{array}{l}\text { PVB group } \\
(n=38)\end{array}$ & $\begin{array}{l}\text { ESPB group } \\
(n=55)\end{array}$ & $P$ value & $\begin{array}{l}\text { PVB group } \\
(n=30)\end{array}$ & $\begin{array}{l}\text { ESPB group } \\
(n=30)\end{array}$ & $P$ value \\
\hline Time for block procedure, sec & $339(259-438)$ & $185(146-243)$ & $<0.0001$ & $300(236-457)$ & $188(148-255)$ & $<0.0001$ \\
\hline Number of dermatomes with loss of cold sensation & & & & & & \\
\hline $15 \min$ & $2(2-3)$ & $0(0)$ & $<0.0001$ & $3(2-4)$ & $0(0)$ & $<0.0001$ \\
\hline After surgery & $4(2.5-5)$ & $0(0-2)$ & $<0.0001$ & $4(2-5)$ & $I(0-3)$ & 0.002 \\
\hline $6 \mathrm{~h}$ & $3(2-4)$ & $0(0-2)$ & $<0.0001$ & $3(2-4)$ & $0(0-I)$ & $<0.0001$ \\
\hline $12 \mathrm{~h}$ & $0(0-2)$ & $0(0-1)$ & 0.145 & $0(0-2)$ & $0(0)$ & 0.174 \\
\hline
\end{tabular}

Note: Data are presented as the median (interquartile range).

Abbreviations: PVB, paravertebral block; ESPB, erector spinae plane block. 
after breast surgery. The median PACU length of stay was $105 \mathrm{~min}$ and $124 \mathrm{~min}$ in the TPVB and ESPB groups, respectively. ${ }^{14}$ Thus, considering that blocks and sensory assessment (30 min later) were conducted before induction of general anesthesia and that the median surgical duration was about $70 \mathrm{~min}$, the data in their study were collected at a time point similar to $6 \mathrm{~h}$ after blocks in the present study. In addition, they studied non-mastectomy patients including bilateral and reconstruction surgery, both of which should be more invasive than the procedure included in the present study. Taken together, it appears that TPVB is more potent than ESPB when the pain intensity is relatively high.

The results of recent cadaver and animal studies have also indicated that TPVB and ESPB have different mechanisms of action. Most cadaveric studies examining the spread of ESPB have shown extensive longitudinal and lateral spread of dye deep and superficial to and inside the erector spinae muscles, but little spread to the paravertebral space that is the main target of TPVB because that area includes both the ventral and dorsal rami of the thoracic nerves. ${ }^{18-23}$

One of the most apparent advantages of ESPB is its lower demand for technical expertise. We showed that ESPB was performed in a shorter period of time than TPVB, as previous studies have shown. ${ }^{14,31}$ This can be explained by the following two reasons. First, TPVB requires more careful needle handling and advancement of a needle for a longer distance to the target. Second, because the spread of injectate in the craniocaudal direction is limited with TPVB, multiple level injections are recommended and conducted in many institutions (including ours) for breast surgery which sometimes affects an extensive dermatomal area (from T1 to T7). ${ }^{32,33}$

There are some limitations to this study. First, this is a retrospective study. Propensity score matching analysis must have reduced the risk of selection bias to some degree, but not eliminated it. It is possible that the choice of ESPB was made because of the less than ideal quality of ultrasound images available when the blocks were conducted. The quality of ultrasound image may affect the resultant effects of blocks differently for each technique. Second, using different techniques for each block may change the results. For example, as discussed above, the number of injection levels for TPVB may affect the block effects. It is possible that a larger number of injection levels result in a wider, more intense blockade. Thus, more than two injections for TPVB might have resulted in different results; postoperative analgesia for $24 \mathrm{~h}$ after ESPB might have been proved to be inferior to that after TPVB. The volume and concentration of local anesthetic possibly affect the spread and sensory blockade, ${ }^{19}$ and thus a larger volume and/or higher concentration of local anesthetic may produce better sensory blockade and analgesic effects with either block. Third, we did not include cancer location in our confounders for propensity score analysis, and it is possible that the two groups differed in the number of patients with cancer in the inner quadrants. Taketa et al showed that hypoesthesia in the parasternal region after ESPB was not obtained as clearly as after TPVB, ${ }^{16,30}$ which suggests that ESPB is inferior to TPVB in relieving pain originating from a surgical procedure in that region. Thus, results might have been different when cancer location had been used as a confounder. Fourth, no blocks were conducted besides TPVB or ESPB. The innervation of the regions where breast surgery is conducted is complex and may include nerves other than upper thoracic spinal nerves such as medial and lateral pectoral nerves. Thus, conducting additional blocks, eg, pecs block or serratus anterior plane block may improve analgesia and may have resulted in different conclusions.

\section{Conclusion}

ESPB and TPVB provided comparable postoperative analgesia for $24 \mathrm{~h}$ in patients undergoing breast surgery. Dermatomal sensory blockade was, however, less apparent and narrower after ESPB than after TPVB. These findings need to be confirmed in future prospective studies.

\section{Data Sharing Statement}

The data can be available upon reasonable request.

\section{Author Contributions}

All authors made a significant contribution to the work reported, whether that is in the conception, study design, execution, acquisition of data, analysis and interpretation, or in all these areas; took part in drafting, revising or critically reviewing the article; gave final approval of the version to be published; have agreed on the journal to which the article has been submitted; and agree to be accountable for all aspects of the work.

\section{Funding}

Departmental funding only.

\section{Disclosure}

Dr Yoji Saito reports personal fees from Shionogi, Daiichi Sankyo, Kyowa Kirin, Hisamitsu, Phizer, Asahi Kasei, Nipponzoki, Tsumura, and Ayumi-pharma, outside the submitted work. The authors report no other conflicts of interest in this work. 


\section{References}

1. Fecho K, Miller NR, Merritt SA, Klauber-Demore N, Hultman CS, Blau WS. Acute and persistent postoperative pain after breast surgery. Pain Med. 2009;10(4):708-715. doi:10.1111/j.1526-4637.2009.00611.x

2. Moller JF, Nikolajsen L, Rodt SA, Ronning H, Carlsson PS. Thoracic paravertebral block for breast cancer surgery: a randomized double-blind study. Anesth Analg. 2007;105(6):1848-1851. doi:10.1213/01.ane.0000286135.21333.fd

3. Schnabel A, Reichl SU, Kranke P, Pogatzki-Zahn EM, Zahn PK. Efficacy and safety of paravertebral blocks in breast surgery: a meta-analysis of randomized controlled trials. $\mathrm{Br} J$ Anaesth 2010;105(6):842-852. doi:10.1093/bja/aeq265

4. Kairaluoma PM, Bachmann MS, Rosenberg PH, Pere PJ. Preincisional paravertebral block reduces the prevalence of chronic pain after breast surgery. Anesth Analg. 2006;103(3):703-708. doi:10.1213/01.ane.0000230603.92574.4e

5. Karmakar MK, Samy W, Li JW, et al. Thoracic paravertebral block and its effects on chronic pain and health-related quality of life after modified radical mastectomy. Reg Anesth Pain Med. 2014;39 (4):289-298. doi:10.1097/AAP.0000000000000113

6. Terheggen MA, Wille F, Borel Rinkes IH, Ionescu TI, Knape JT. Paravertebral blockade for minor breast surgery. Anesth Analg. 2002;94(2):355-359. doi:10.1097/00000539-200202000-00023

7. Piraccini E, Pretto EAJ, Corso RM, Gambale G. Analgesia for thoracic surgery: the role of paravertebral block. HSR Proc Intensive Care Cardiovasc Anesth. 2011;3(3):157-160.

8. Forero M, Adhikary SD, Lopez H, Tsui C, Chin KJ. The erector spinae plane block: a novel analgesic technique in thoracic neuropathic pain. Reg Anesth Pain Med. 2016;41(5):621-627. doi:10.1097/ AAP.0000000000000451

9. Kot P, Rodriguez P, Granell M, et al. The erector spinae plane block: a narrative review. Korean J Anesthesiol. 2019;72(3):209-220. doi:10.4097/kja.d.19.00012

10. Gürkan Y, Aksu C, Kuş A, Yörükoğlu UH, Kılıç CT. Ultrasound guided erector spinae plane block reduces postoperative opioid consumption following breast surgery: a randomized controlled study. J Clin Anesth. 2018;50:65-68. doi:10.1016/j.jclinane.2018.06.033

11. Gürkan Y, Aksu C, Kuş A, Yörükoğlu UH. Erector spinae plane block and thoracic paravertebral block for breast surgery compared to IV-morphine: a randomized controlled trial. J Clin Anesth 2020;59:84-88. doi:10.1016/j.jclinane.2019.06.036

12. ElHawary H, Abdelhamid K, Meng F, Janis JE. Erector spinae plane block decreases pain and opioid consumption in breast surgery. Plast Reconstr Surg Glob Open. 2019;7(11):e2525. doi:10.1097/ GOX.0000000000002525

13. El Ghamry M, Amer AF. Role of erector spinae plane block versus paravertebral block in pain control after modified radical mastectomy. A prospective randomised trial. Indian $J$ Anaesth. 2019;63 (12):1008-1014. doi:10.4103/ija.IJA_310_19

14. Swisher MW, Wallace AM, Sztain JF, et al. Erector spinae plane versus paravertebral nerve blocks for postoperative analgesia after breast surgery: a randomized clinical trial. Reg Anesth Pain Med. 2020;45(4):260-266. doi:10.1136/rapm-2019-101013

15. De Cassai A, Tonetti T. Local anesthetic spread during erector spinae plane block. J Clin Anesth. 2018;48:60-61. doi:10.1016/j. jclinane.2018.05.003

16. Taketa Y, Irisawa Y, Fujitani T. Ultrasound-guided erector spinae plane block elicits sensory loss around the lateral, but not the parasternal, portion of the thorax. J Clin Anesth. 2018;47:84-85. doi:10.1016/j.jclinane.2018.03.023

17. Righetti R, Kozhevnikova I, Nencini C, et al. Combination of erector spinae plane block at $\mathrm{T} 2$ and $\mathrm{T} 5$ for quadrantectomy and sentinel lymph node biopsy. J Clin Anesth. 2020;61:109637. doi:10.1016/j. jclinane.2019.109637
18. Nielsen M, Moriggl B, Hoermann R, Nielsen TD, Bendtsen TF, Børglum J. Are single-injection erector spinae plane block and multiple-injection costotransverse block equivalent to thoracic paravertebral block? Acta Anaesthesiol Scand. 2019;63(9):1231-1238. doi:10.1111/ aas. 13424

19. Choi YJ, Kwon HJ, O J. Influence of injectate volume on paravertebral spread in erector spinae plane block: an endoscopic and anatomical evaluation. PLoS One. 2019;14(10):e224487. doi:10.1371/ journal.pone. 0224487

20. Ivanusic J, Konishi Y, Barrington MJ. A cadaveric study investigating the mechanism of action of erector spinae blockade. Reg Anesth Pain Med. 2018;43(6):567-571. doi:10.1097/AAP. 0000000000000789

21. Yang HM, Choi YJ, Kwon HJ, Cho TH, Kim SH, Kim SH. Comparison of injectate spread and nerve involvement between retrolaminar and erector spinae plane blocks in the thoracic region: a cadaveric study. Anaesthesia. 2018;73(10):1244-1250. doi:10.1111/anae.14408

22. Dautzenberg KHW, Zegers MJ, Bleeker CP, et al. Unpredictable injectate spread of the erector spinae plane block in human cadavers. Anesth Analg. 2019;129(5):e163-e166. doi:10.1213/ ANE.0000000000004187

23. Otero PE, Fuensalida SE, Russo PC, Verdier N, Blanco C, Portela DA. Mechanism of action of the erector spinae plane block: distribution of dye in a porcine model. Reg Anesth Pain Med. 2020;45(3):198-203. doi:10.1136/rapm-2019-100964

24. Shibata Y, Nishiwaki K. Ultrasound-guided intercostal approach to thoracic paravertebral block. Anesth Analg. 2009;109(3):996-997. doi:10.1213/ane.0b013e3181af7e7b

25. Blaivas M, Lyon M, Duggal SA. Prospective comparison of supine chest radiography and bedside ultrasound for the diagnosis of traumatic pneumothorax. Acad Emerg Med. 2005;12(9):844-849. doi:10.1197/j.aem.2005.05.005

26. Habib AS, Kertai MD, Cooter M, Greenup RA, Hwang S. Risk factors for severe acute pain and persistent pain after surgery for breast cancer: a prospective observational study. Reg Anesth Pain Med. 2019;44(2):192-199. doi:10.1136/rapm-2018-000040

27. Abdallah FW, Cil T, MacLean D, et al. Too deep or not too deep?: a propensity-matched comparison of the analgesic effects of a superficial versus deep serratus fascial plane block for ambulatory breast cancer surgery. Reg Anesth Pain Med. 2018;43(5):480-487. doi:10.1097/AAP.0000000000000768

28. Gallagher EJ, Liebman M, Bijur PE. Prospective validation of clinically important changes in pain severity measured on a visual analog scale. Ann Emerg Med. 2001;38(6):633-638. doi:10.1067/mem. 2001.118863

29. Cepeda SM, Africano JM, Polo R, Alcala R, Carr DB. What decline in pain intensity is meaningful to patients with acute pain? Pain. 2003;105(1):151-157. doi:10.1016/S0304-3959(03) 00176-3

30. Taketa Y, Irisawa Y, Fujitani T. Comparison of ultrasound-guided erector spinae plane block and thoracic paravertebral block for postoperative analgesia after video-assisted thoracic surgery: a randomized controlled non-inferiority clinical trial. Reg Anesth Pain Med. 2020;45(1):10-15. doi:10.1136/rapm-2019-100827

31. Moustafa M, Alabd A, Ahmed A, Deghidy E. Erector spinae versus paravertebral plane blocks in modified radical mastectomy: randomised comparative study of the technique success rate among novice anaesthesiologists. Indian J Anaesth. 2020;64(1):49-54. doi:10.4103/ija. IJA $536 \quad 19$

32. Naja ZM, El-Rajab M, Al-Tannir MA, et al. Thoracic paravertebral block: influence of the number of injections. Reg Anesth Pain Med. 2006;31(3):196-201. doi:10.1016/j.rapm.2005.12.004

33. Kasimahanti R, Arora S, Bhatia N, Singh G. Ultrasound-guided single- vs double-level thoracic paravertebral block for postoperative analgesia in total mastectomy with axillary clearance. J Clin Anesth. 2016;33:414-421. doi:10.1016/j.jclinane.2016.01.027 


\section{Publish your work in this journal}

The Journal of Pain Research is an international, peer reviewed, open access, online journal that welcomes laboratory and clinical findings in the fields of pain research and the prevention and management of pain. Original research, reviews, symposium reports, hypothesis formation and commentaries are all considered for publication. The manuscript management system is completely online and includes a very quick and fair peer-review system, which is all easy to use. Visit http:// www.dovepress.com/testimonials.php to read real quotes from published authors. 